\title{
LAS PINTURAS DEL RETABLO MAYOR DE LA IGLESIA DEL REAL HOSPITAL DE SAN LÁZARO DE SEVILLA
}

\author{
Matilde Fernández Rojas \\ Universidad de Sevilla \\ maty@us.es
}

\section{RESUMEN}

El breve estudio que presentamos es parte de un trabajo en curso sobre la historia, la arquitectura y el patrimonio artístico del Real Hospital de San Lázaro de Sevilla, el más antiguo de la ciudad y el primero de fundación real, que mantiene su función asistencial hasta hoy. Exponemos lo hasta ahora conocido sobre las pinturas realizadas en 1553 por los maestros Pedro de Villegas Marmolejo y Juan Chacón para el retablo mayor de la iglesia, algunas de las cuales han permanecido en un retablo posterior de estilo barroco. Afortunadamente el conjunto pictórico está siendo restaurado en el Instituto Andaluz de Patrimonio Histórico (IAPH).

Palabras clave: Sevilla, retablo, pintura, Hospital de San Lázaro, Pedro de Villegas Marmolejo, Juan Chacón.

\section{THE PAINTINGS OF THE MAIN ALTABLES OF THE CHURCH \\ OF THE REAL HOSPITAL OF SAN LÁZARO DE SEVILLA}

\section{Abstract}

The brief study that we present is part of an ongoing work on the history, architecture and artistic heritage of the Real Hospital de San Lázaro in Seville, the oldest in the city and the first and only one with a royal foundation, which maintains its function care until today. We present what is known so far about the paintings made in 1553 by the masters Pedro de Villegas Marmolejo and Juan Chacón for the main altarpiece of the church, some of which have remained in a later Baroque style altarpiece. Fortunately, the pictorial set is being restored at the Andalusian Institute of Historical Heritage (IAPH).

Keywords: Seville, altarpiece, painting, Hospital de San Lázaro, Pedro de Villegas Marmolejo, Juan Chacón. 
El 17 de julio de 1553 el mayoral del hospital del Real Hospital de San Lázaro de Sevilla, Antonio Bélez de Alcoçer, contrataba la realización del dorado y las pinturas del retablo mayor de la iglesia con los maestros Pedro de Villegas Marmolejo y Juan Chacón, por el precio de setenta ducados ${ }^{1}$. El retablo, cuya autoría y fecha de ejecución se desconoce, no se ha conservado pero sí algunas de las diez pinturas que se estipularon en el contrato, que posteriormente serían embutidas en un retablo barroco de autor anónimo considerado de principios del siglo XVIII.

La institución hospitalaria fue fundada y patrocinada por el rey Alfonso X el Sabio en 1253, siendo engrandecida y privilegiada por los monarcas posteriores. Su finalidad era recoger, alimentar y curar a los enfermos de lepra del arzobispado de Sevilla y del obispado de Cádiz, un uso sanitario que ha mantenido ininterrumpidamente desde la Edad Media hasta nuestros días, aunque con un cambio de patologías a tratar, siendo por tanto el hospital más antiguo de Sevilla, el primero de fundación real, aunque muy alterado y modificado en su transcurrir durante más de setecientos ańos de historia.

Para su emplazamiento se eligió un lugar extramuros, como era preceptivo en la instalación de lazaretos, a unos dos kilómetros de la ciudad desde la Puerta de la Macarena, en un paraje próximo al Guadalquivir y, aunque apartado, bien comunicado con la urbe a través de la antigua calzada romana (Collantes 1844, I, pp. 12 y 13) que pasó a denominarse "Carrera de San Lázaro» (Ortiz de Zúñiga 1795, I, p. 327) desde la referida puerta al sitio del hospital.

El punto de partida fue una torre medieval existente con anterioridad a la conquista cristiana, denominada de los Gausines, hermanos alarifes musulmanes que al parecer la edificaron y que tenía un carácter defensivo y militar; así lo explicitan antiguos cronistas como Morgado (1587, fol. 120), «está a poco trecho de la ciudad pegada con ella una torre», y Ortiz de Zúńiga (1795, I, pp. 41-44), «la torre a que está arrimado el hospital de S. Lázaro». La noción sobre el primitivo hospital apenas si la podemos rastrear en las Ordenanzas de $1393^{2}$ : un conjunto de sencillas viviendas donde habitaban los enfermos y una modesta capilla, antecedente de la posterior iglesia edificada entre finales del Xv para el cuerpo del templo y primera mitad del XVi para la bóveda del presbiterio, según concluye en su tesis Vilaplana (2017, I, p. 194). Igualmente, el recinto hospitalario participó de una serie de transformaciones emprendidas desde finales del siglo xv y continuadas en la segunda mitad del xvi, con la construcción de diferentes unidades funcionales que le dieron una nueva configuración: un conjunto cuadrangular en torno a un patio principal al que abrían las salas, una fachada manierista que arranca de la referida torre de los Gausines hacia el norte, inspirada en algunos de los diseńos recogidos en el Libro de Architectura del tratadista italiano Serlio, y cuya traza se atribuye al arqui-

${ }_{1}$ El contrato de las pinturas del retablo fue dado a conocer por López Martínez, C. (1929, pp. 171-172).

2 Se trata de un traslado o copia de 1494 de las Ordenanzas del Hospital de San Lázaro, redactadas en 1393, que se encuentran en el Archivo Histórico de la Diputación Provincial de Sevilla, legajo 4, 1, 1. 


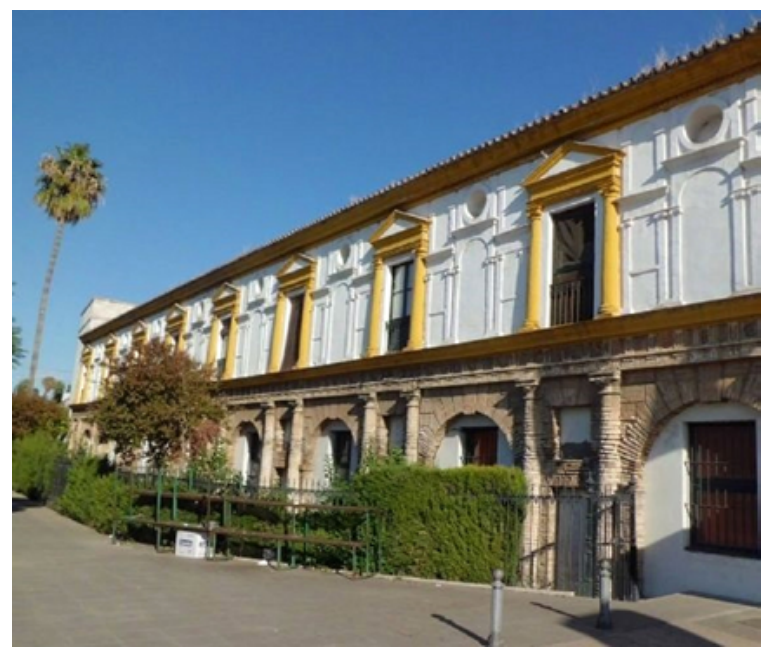

Fig. 1. Fachada del Real Hospital de San Lázaro de Sevilla, atribuida a Hernán Ruiz II, mediados del siglo XvI.

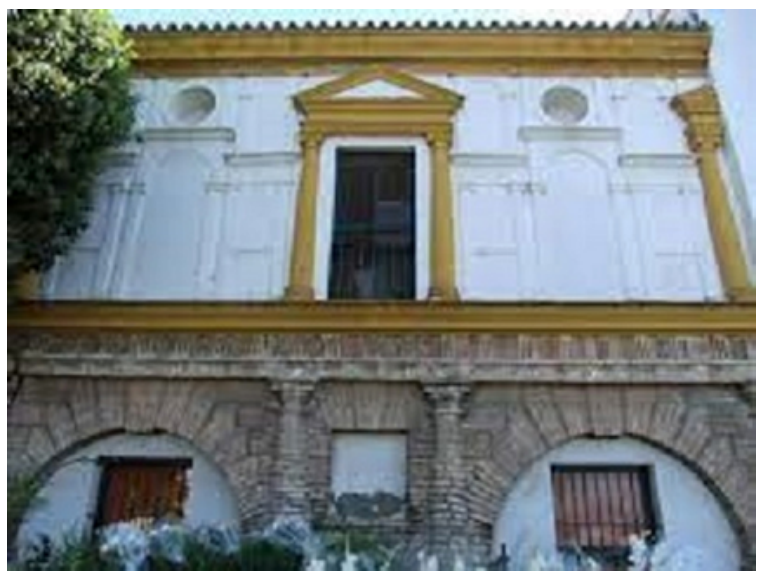

Fig. 2. Detalle de la fachada del Real Hospital de San Lázaro de Sevilla, mediados del siglo XVI.

tecto Hernán Ruiz II (Morales 1982, p. 154. Cómez 1991, pp. 49-52) (figuras 1 y 2); en la torre se abrió la portada principal de acceso al lazareto (figura 3), quedando la iglesia emplazada en el lado meridional, a la que en el siglo XviII se le antepuso una crujía de fachada que enlazaba con la torre, conformándose así un frente unido y parejo. Esta alteración significó el desmontaje de la puerta del templo a la nueva 


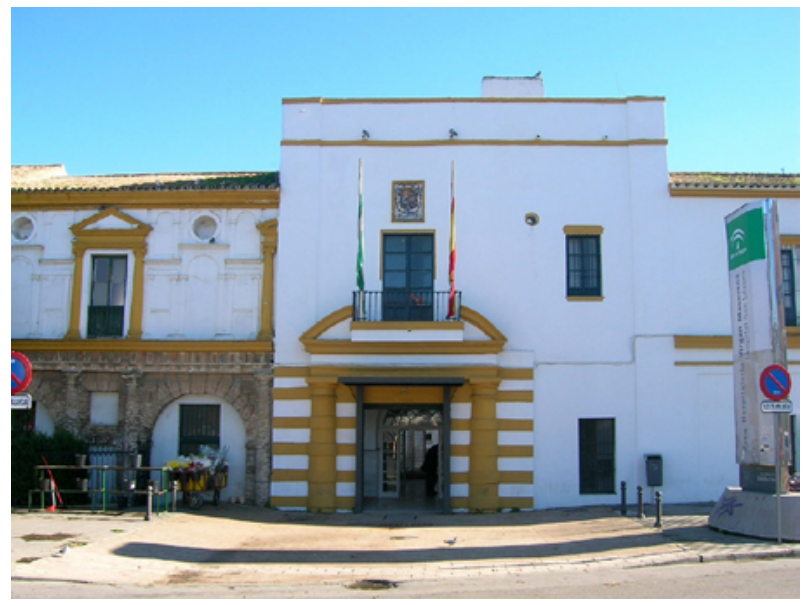

Fig. 3. Portada de acceso al Real Hospital de San Lázaro de Sevilla, siglo XviII.

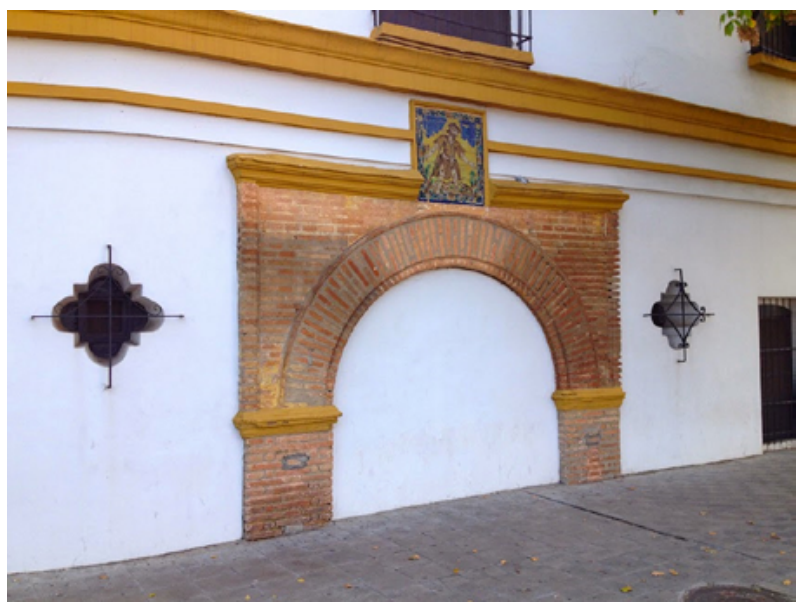

Fig. 4. Portada de la iglesia del Real Hospital de San Lázaro de Sevilla, finales del siglo xv.

fachada, donde aún se conserva aunque cegada y rehundida por la subida de la cota de la calle (figura 4).

La iglesia, pese a su lamentable estado de deterioro y a sus desafortunadas alteraciones a lo largo del tiempo, constituye una pieza de gran interés arquitectónico, cultural y simbólico. Era el recinto sagrado donde los desafortunados y estigmatizados enfermos elevaban sus plegarias, cumplían con sus obligaciones religiosas y donde los enfermos podían contraer matrimonio -a lo que estaban autorizados-y bautizar a sus hijos, por tener el templo condición de parroquia y contar con cape- 


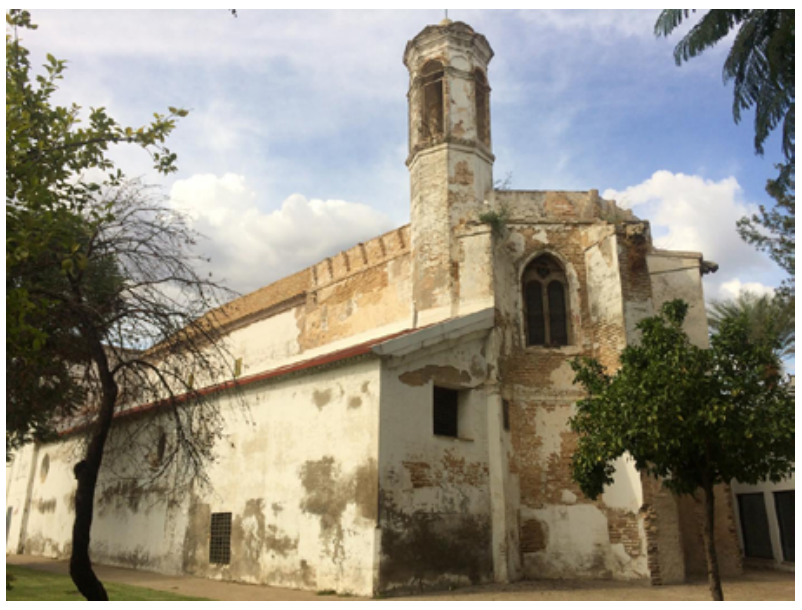

Fig. 5. Exterior de la iglesia del Real Hospital de San Lázaro de Sevilla, primera mitad del siglo XVI.

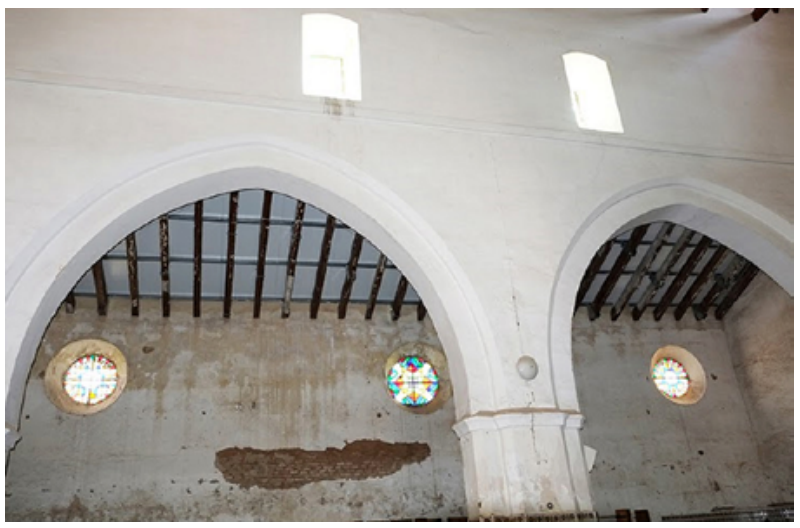

Fig. 6. Vistas del interior de la iglesia del Real Hospital de San Lázaro de Sevilla, en su estado actual.

llán. Formalmente responde a las características de las iglesias gótico-mudéjares sevillanas, de planta basilical de tres naves, la central más ancha y elevada, separadas mediante arcos apuntados que apean sobre pilares cruciformes, y cubierta contemporánea de madera, en forma de artesa la central y de colgadizo las laterales. La cabecera presenta un profundo ábside poligonal cubierto con bóveda de terceletes muy alongada, cuyos nervios descansan en ménsulas decoradas con motivos vegetales, dos ventanas bíforas lanceoladas en el frente, y al exterior cuatro robustos contrafuertes, un coronamiento de almenas escalonadas sobre el antepecho y cubierta a dos aguas en el cuerpo del templo. En el lado derecho del ábside se levanta la torre campanario octogonal, con arcadas y frontones triangulares y curvos que alternan 

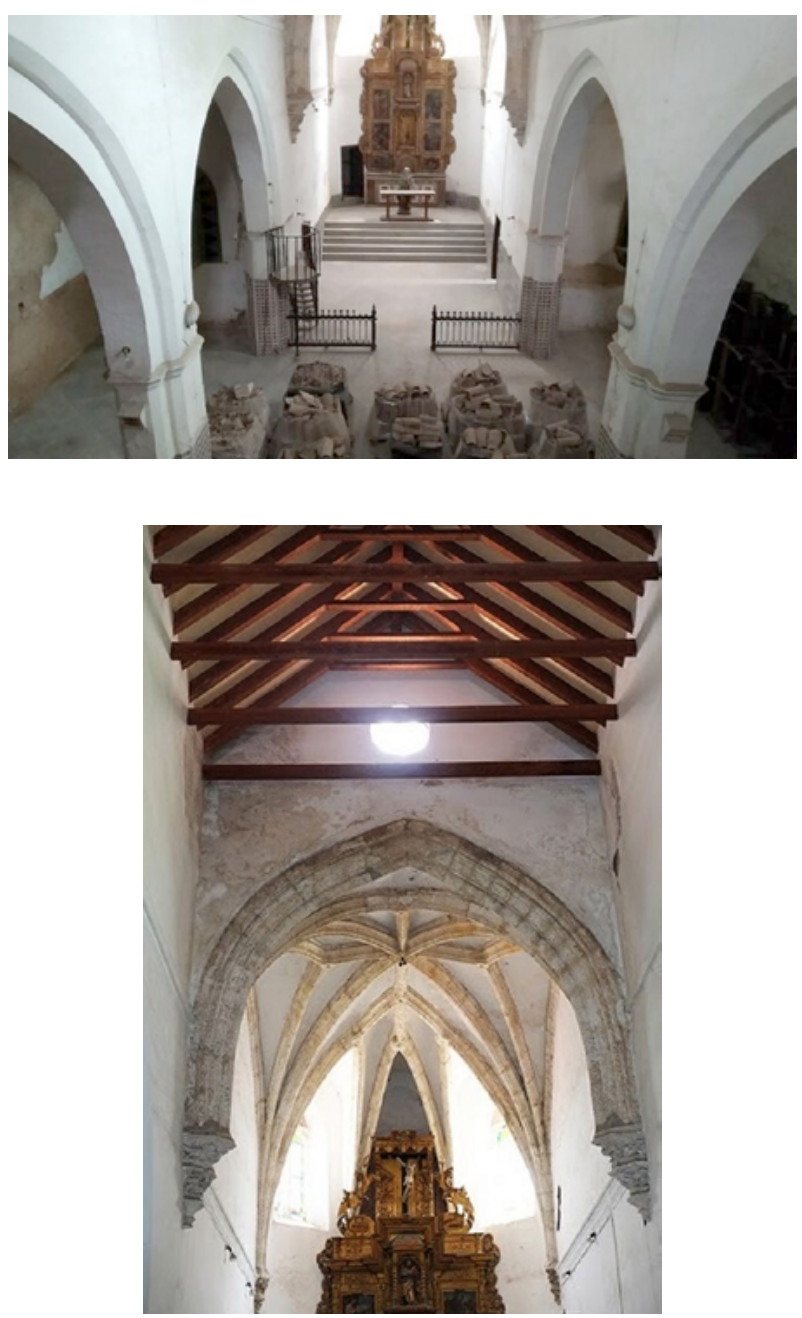

Figs. 7 y 8 . Vistas del interior de la iglesia del Real Hospital de San Lázaro de Sevilla, en su estado actual.

con huecos ciegos en el cuerpo de campanas y cuya construcción se considera de la segunda mitad del siglo Xvi (Cómez 1991, p. 49) (figuras 5, 6, 7 y 8).

La portada del templo (figura 4), que como ya hemos referido fue removida de su emplazamiento original en el hastial de los pies de la nave central, está realizada en ladrillo agramilado y se configura mediante un arco de medio punto enmarcado por un gran alfiz de ladrillo igualmente agramilado. Al momento de su traslado en el siglo XVIII corresponde el azulejo situado en su parte superior con la imagen de san Lázaro en su iconografía de pobre leproso acompañado de los perros 


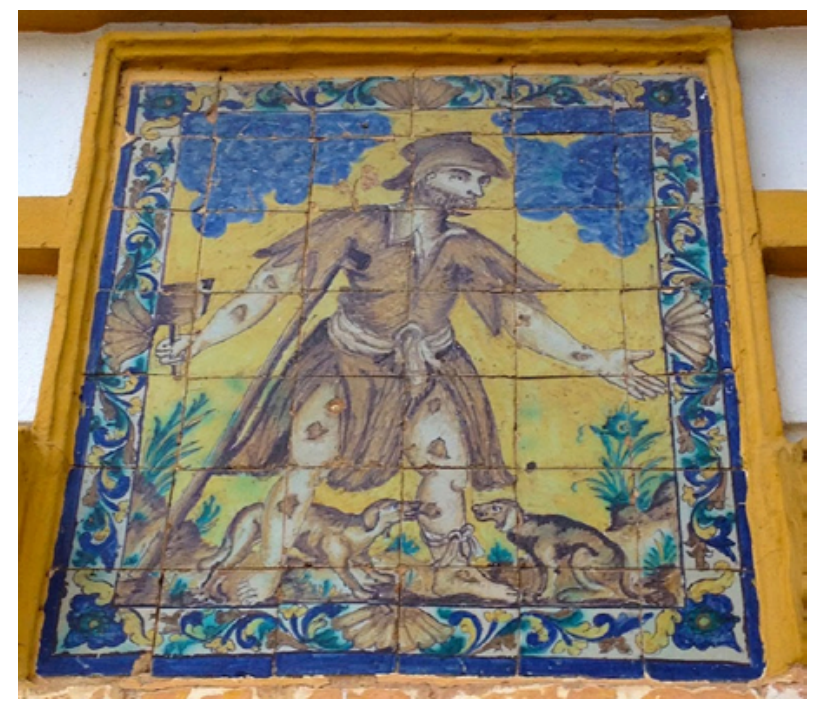

Fig. 9. San Lázaro, azulejo del siglo Xviı perteneciente a la portada de la iglesia del Real Hospital de San Lázaro de Sevilla.

que lamen sus heridas, y sosteniendo las tablillas o tarreñas en la mano con cuyo repiqueteo advierte de su presencia y solicita limosna (figura 9).

En el interior de la iglesia aún permanece el retablo barroco (figura 10) donde, en fecha desconocida, se insertaron las pinturas debidas a Villegas Marmolejo y a Juan Chacón. Se trata de un retablo marco ideado como soporte de las pinturas preexistentes, es de madera tallada y dorada, de planta rectilínea y su alzado se compone de banco con sagrario, dos cuerpos de tres calles separadas por sencillas molduras y una cornisa escalonada que da paso al ático. En el centro de primer cuerpo se abre un camarín, ahora vacío, que debió contener un manifestador o esculturas de la Virgen o del Sagrado Corazón, como se aprecia en antiguas fotografías. En el centro de segundo cuerpo se dispone una hornacina a modo de templete, sustentada por cuatro columnas salomónicas en cuyo interior se sitúa el grupo escultórico San José con el Niño, obra de autor desconocido fechable a principio del siglo XVIII. En el interior de la estructura rectangular del ático se halla la escultura del Crucificado, anónimo y datable a mediados del xvi. La estructura arquitectónica es sencilla, patente en el molduraje gallonado que enmarca los paneles pictóricos conservados de mano de los referidos Villegas y Chacón. Son los elementos decorativos los que aportan un mayor énfasis plástico al conjunto, en el que se ha dispuesto a modo de orla o ribete exterior una serie de tarjas carnosas, racimos frutales y volutas enrolladas, una labor de talla que en el ático se hace sinuosa, casi volátil, con el desarrollo de dos formas que serpentean colocadas a cada lado de la caja central. 


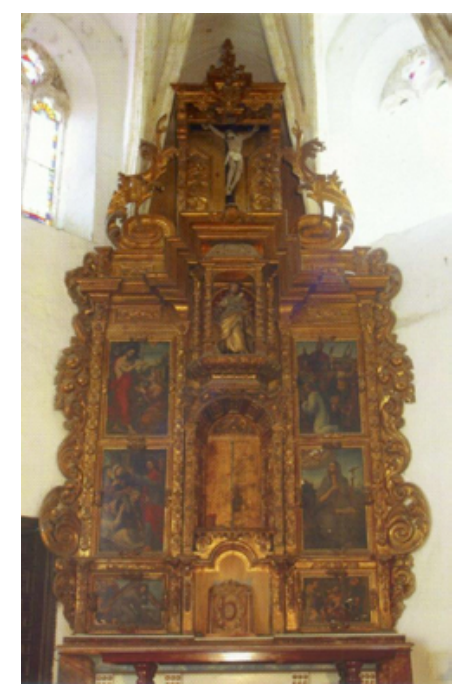

Fig. 10. Retablo mayor de la iglesia del Real Hospital de San Lázaro de Sevilla, anónimo de principios del siglo XviII.

Hay que señalar que en la sacristía de la iglesia se refiere la existencia de una escultura de San Lázaro obispo $(76,5 \times 27 \mathrm{~cm})$, realizada en madera tallada, estofada y policromada, que fue atribuida a Roque Balduque y datada hacia 1555 (Torre Ruiz 1992, pp. 31-33), y cuyo paradero actual desconocemos. La figura está sin tallar en su parte posterior, sólo desbastada la madera, por lo que fue ideada para ser adosada, quizás a algún retablo colateral de la iglesia o al mayor con anterioridad al realizado en pintura por Villegas Marmolejo; puede tratarse del que en 1844 cita González de León (II, p. 246): «En el altar mayor está el Santo titular S. Lázaro Obispo», toda vez que la pintura de Villegas ya no se hallaba en su lugar por haber sido requisada por los franceses. Desde el punto de vista iconográfico el santo se ha representado en su calidad de obispo, dignidad adquirida en Marsella, a donde, según el relato medieval de Santiago de la Vorágine transmitido en su Leyenda Dorada (II, p. 75), Lázaro de Betania arribó con sus hermanas Marta y María tras salir de Palestina a causa de la persecución contra los cristianos. Otra modalidad en la manera de efigiarlo es la que vemos en el referido azulejo dieciochesco que preside la portada del templo, en su condición de leproso, enfermedad que al parecer padecía antes de ser resucitado por Jesucristo. El santo se halla de pie, sosteniendo un libro con su mano izquierda y la derecha en actitud de portar un báculo, hoy inexistente, con capelo y mitra en la cabeza. Está revestido con sotana adornada con motivos florales dorados sobre fondo negro, alba con dibujos imitando encaje y capa pluvial abrochada al pecho con un cabujón trilobulado y con su borde inferior recorrido por flecos; su interior está pintado en rojo con adornos dorados a base de hojas y el exterior con faunos, putti, cornucopias y candelieri. El rostro presenta una buena factura, marcado ángulo facial, expresiva mirada y excelente encarnación de pulimento, es decir, 
brillante, técnica practicada en este periodo. Sabemos que Villegas, además de pintor, fue un estimable estofador, de lo cual se han conservado algunos ejemplos; la calidad que presenta el estofado de esta escultura lleva a pensar que bien pudo encargarse de realizar en ella esta labor, idea que puede quedar reforzada con la conocida relación entre ambos maestros, cuando Villegas actúa como fiador de Balduque en el retablo de la iglesia de San Lorenzo de Sevilla, en 1558.

\section{LAS PINTURAS}

Cuando se firma el contrato de ejecución del dorado y las pinturas del retablo éste ya estaba realizado y asentado en el presbiterio de la iglesia, como se desprende de lo referido en la escritura que mancomunadamente firman Villegas Marmolejo y Chacón, quienes se obligan a pintar los «diez tableros entre grandes y pequeños queste Retablo tiene». Asimismo, se indicaban las historias a pintar y su distribución, lo que permite conocer el programa iconográfico y la estructura arquitectónica del retablo, compuesto de banco, dos cuerpos de tres calles y ático. En los tres compartimentos de que constaba el banco, «en el principal de en medio a de yr la quinta angustia con san juan y la magdalena», en el de la derecha Cristo con la cruz a cuestas y en el de la izquierda la Coronación de espinas, disposición que se ha mantenido en el retablo posterior, aunque la Quinta Angustia no se ha conservado. En el tablero central y principal del primer cuerpo «a de yr pintada la imagen de san lazaro obispo vestido de pontifical», en el de la derecha la Resurrección de Lázaro, y en el de la izquierda el Martirio de san Lázaro. De estas tres no se ha conservado el San Lázaro obispo, obra elogiada por Ceán (1800, v, p. 258), quien, por su buena calidad artística, no duda en parangonarla con las de Pedro de Campaña, y de la que sabemos que en 1811 Frederic Quilliet envió a José I a Madrid perdiéndosele la pista desde entonces (Serrera 1991, p. 68). En el segundo cuerpo, en el centro, se dispondría "la asunción de nra. señora con los ángeles que combinieren», y en los tableros laterales a izquierda y derecha respectivamente, «el ángel san Gabriel [...] y la imagen de nra. señora en la salutación"; ninguna de las tres existe, si es que realmente se llegaron a realizar. Finalmente, en el ático un «dios padre con sus nubes y Resplandores», que tampoco se ha conservado.

Hasta nuestros días han llegado un total de seis pinturas: Cristo con la cruz a cuestas, La coronación de espinas, Resurrección de Lázaro, Martirio de san Lázaro, Noli me tangere o Aparición de Cristo a la Magdalena y la Magdalena penitente, advirtiéndose que estas dos últimas no constaban en la escritura del contrato, por lo que hubo de producirse un cambio en el programa iconográfico inicial.

Pedro de Villegas Marmolejo nació en Sevilla en 1519 y aquí murió en 1596, siendo enterrado en la parroquia de San Lorenzo ${ }^{3}$. Pintor erudito, amigo de huma-

3 El primer estudio monográfico sobre la vida y la obra de Villegas Marmolejo, al que nos remitimos, fue realizado por el profesor Serrera (1976). Manejamos la segunda edición, de 1991. 
nistas como Juan de Mal Lara y Benito Arias Montano, a quien nombró su albacea y heredero universal de todos sus bienes, ostentó el cargo de mayordomo de la corporación de los pintores de San Lucas de la ciudad. Destacó de entre los artistas de su generación, desarrollando en su dilatada vida una importante carrera como pintor y como policromador y estofador de imágenes y retablos, actividades realizadas en aquella época por el gremio de pintores. En este sentido se conoce la realización de estas labores en trabajos de Juan Bautista Vázquez el Viejo, Jerónimo Hernández o Gaspar del Águila. Se conservan un buen número de obras de pincel que delatan un estilo pictórico derivado de Rafael y sus seguidores, uniforme a lo largo de su trayectoria artística aunque con cierto amaneramiento en sus últimas obras; a menudo sus composiciones se inspiran en grabados de maestros italianos y flamencos. El encargo de las pinturas del retablo lazarino es el primero documentado conocido hasta ahora de Villegas, afortunadamente conservado en su mayor parte; su envergadura debió consolidar su prestigio en la ciudad, siendo la primera de sus grandes producciones, que hay que encuadrar en la fase inicial de sus trabajos pictóricos, de claro carácter italianizante (Valdivieso 1986, p. 87).

Sobre Juan Chacón se desconocen datos fundamentales como lugar y fecha de nacimiento y maestro con el que se formó; sabemos que en 1548 contaba con taller abierto, pues en esa fecha se documenta la recepción de un aprendiz. Como fecha extrema tenemos la de 1593, año en el que se documenta el contrato de ejecución de las pinturas para las ventanas del convento trinitario de las santas Justa y Rufina de Sevilla. Existen abundantes referencias documentales que dan cuenta de su variado quehacer artístico y salvo las dos tablas que se le adjudican en el retablo de San Lázaro, nada se ha conservado, lo que impide conocer en profundidad su arte. Pintor de sargas, lienzos y de obras de carácter decorativo (Galera Real, fuente en el Alcázar), dorador y policromador de varios retablos y esculturas, tracista (banco y sagrario para el convento sevillano de Santa Paula, en donde ostentó el cargo de mayordomo desde 1566), Chacón se manifiesta como un artista versátil, trabajando para particulares, comerciantes de arte en el mercado americano, así como para el cabildo catedralicio con varios encargos en aderezo y pintura en el cirio pascual, el monumento eucarístico del Jueves Santo, cruces, y dorado de tablas para el altar mayor y de la espada de san Pablo de la Puerta del Perdón. También se constata en la documentación su vinculación en trabajos mancomunados con maestros como Antonio de Alfían, Gaspar del Águila y con nuestro Villegas Marmolejo en las pinturas que nos ocupan, única colaboración conocida hasta ahora entre ambos artistas y la primera noticia relativa a la actividad profesional de Chacón ${ }^{4}$.

Las pinturas realizadas por Juan Chacón se sitúan en el banco del retablo, siendo las escenas representadas Cristo con la cruz a cuestas y La coronación de espinas. Ambas presentan muy mal estado de conservación -actualmente están siendo restauradas-, lo que no ha permitido una valoración más ajustada, que en cualquier caso son de inferior calidad artística a las cuatro restantes debidas a Villegas. Cristo

\footnotetext{
${ }^{4}$ Una reciente aportación a la vida y obra de Juan Chacón en Escuredo (2019, pp. 143-160).
} 


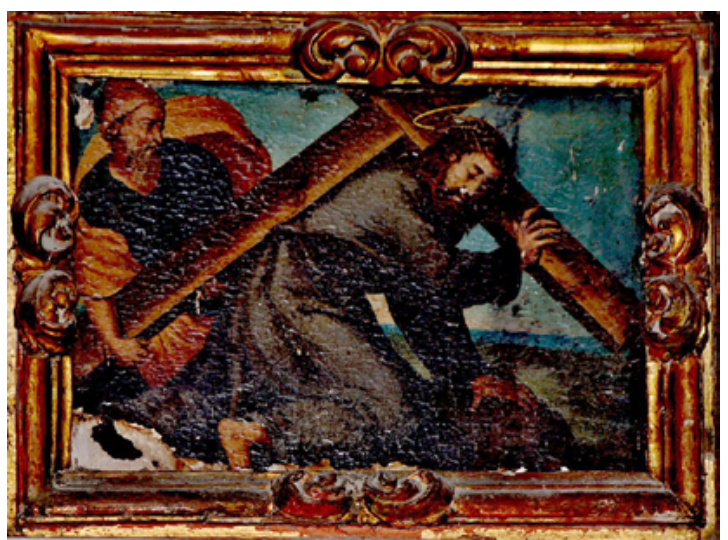

Fig. 11. Juan Chacón, Cristo con la cruz a cuestas, 1553, 41,4 × 60,7 cm, retablo mayor de la iglesia del Real Hospital de San Lázaro, Sevilla, España.
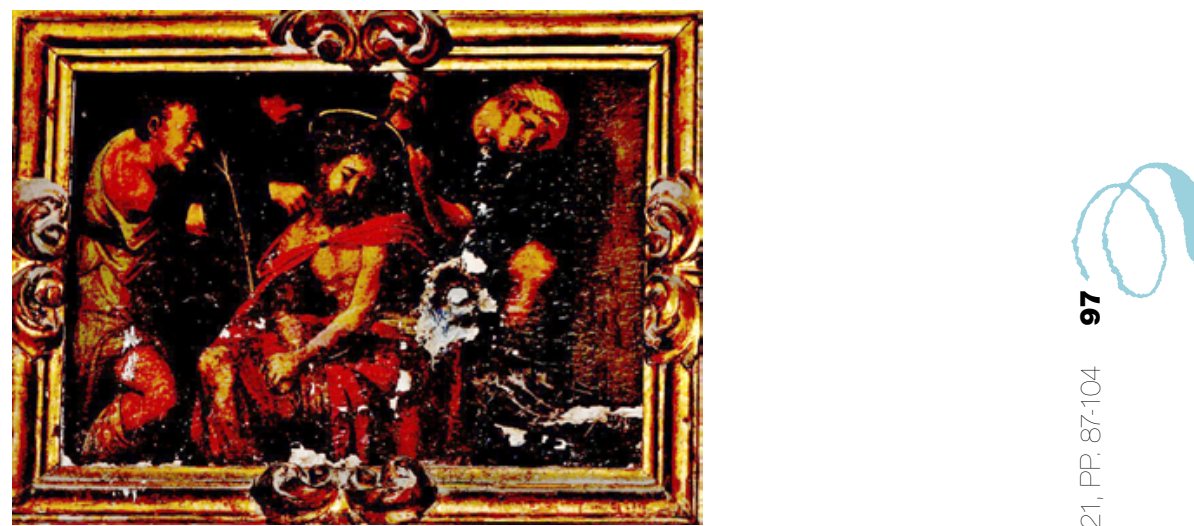

Fig. 12. Juan Chacón. La coronación de espinas, 1553, 41,4 ×60,7 cm, retablo mayor de iglesia del Real Hospital de San Lázaro, Sevilla, España.

con la cruz a cuesta $(41,4 \times 60,7 \mathrm{~cm})$ (figura 11) representa el pasaje evangélico de Jesús camino del Calvario, que, vencido por el peso de la cruz, cae en tierra, apoyando su mano izquierda en una piedra mientras que Simón de Cirene, el Cirineo, situado tras él, le ayuda a portar el madero. La escena presenta una convencional disposición de las figuras, en un plano muy próximo al espectador, con un somero paisaje y una factura muy simple.

La Coronación de espinas $(41,4 \times 60,7 \mathrm{~cm})$ (figura 12) posee un mayor dinamismo y estudio de detalle de los personajes: en el centro la figura sedente de Cristo coronado de espinas recibe mansamente la burla y el escarnio de los dos sayones dispuestos a los lados; de la ambientación nocturna de la escena emergen las tres figu- 


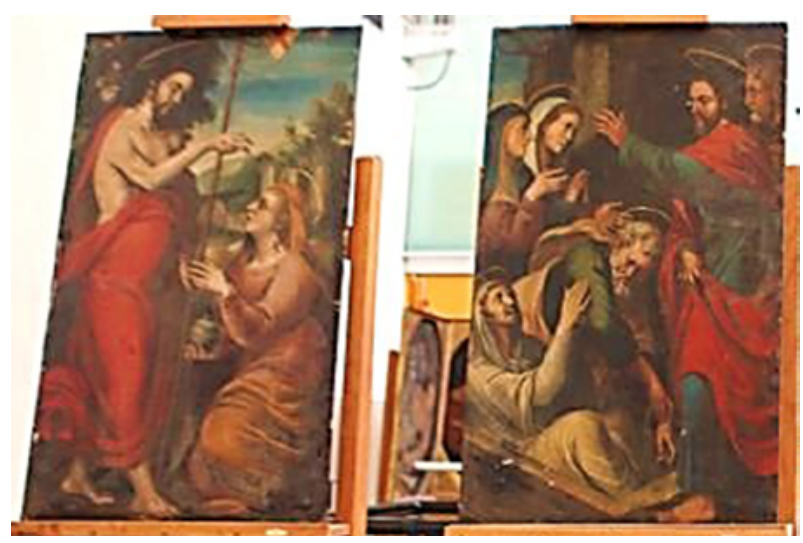

Fig 13. Pedro de Villegas Marmolejo, Noli me tangere o Aparición de Cristo a la Magdalena y Resurrección de Lázaro, $1553,105 \times 60 \mathrm{~cm}$, retablo mayor de la iglesia del Real Hospital de San Lázaro, Sevilla, España.

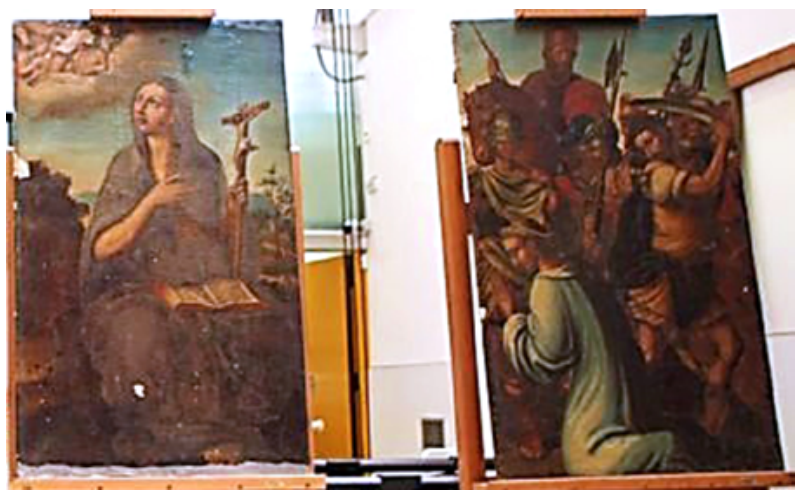

Fig. 14. Pedro de Villegas Marmolejo, Magdalena penitente y Martirio de san Lázaro, 1553, $105 \times 60 \mathrm{~cm}$, retablo mayor de la iglesia del Real Hospital de San Lázaro, Sevilla, España.

ras en las que se aprecia un estudio de colorido más matizado en las vestimentas, enfatizado por el rojo de la túnica de Jesús.

De las cuatro pinturas salidas del pincel de Villegas Marmolejo, dos representan episodios de la vida del santo, la Resurrección de Lázaro y el Martirio de san Lázaro, cuya ubicación en el plan del retablo quedó establecida en el contrato, en las calles laterales del primer cuerpo, aunque en mudanzas posteriores esta disposición fue alterada. Las otras dos pinturas debidas a Villegas representan los pasajes evangélicos del Noli me tangere o Aparición de Cristo a la Magdalena y la Magdalena penitente, temas no recogidos en el contrato de ejecución de las pinturas, como ya hemos referido (figuras 13 y 14). 


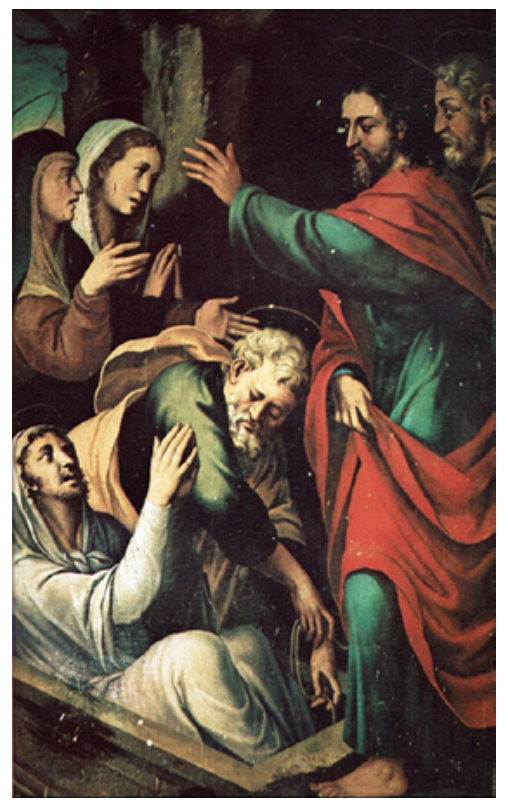

Fig. 15. Pedro de Villegas Marmolejo, Resurrección de Lázaro, 1553, $105 \times 60 \mathrm{~cm}$, retablo mayor de la iglesia del Real Hospital de San Lázaro, Sevilla, España.

La Resurrección de Lázaro $(105 \times 60 \mathrm{~cm})$ (figura 15) representa el pasaje del Evangelio de san Juan (11: 17-44) de la resurrección de Lázaro de Betania por Jesucristo, una de las tres resurrecciones milagrosas que se le adjudican. La composición se ordena en una serie de diagonales escalonadas, con Lázaro en primer plano que se incorpora del sarcófago y dirige su mirada a Cristo mientras que un varón se apresta a desembarazarlo de la mortaja blanca que lo envuelve. Detrás se sitúan sus hermanas, Marta y María, mirando a Jesús, que se halla situado de pie al otro lado de la escena, con el brazo izquierdo extendido sobre Lázaro mientras que otra figura masculina detrás de él asiste al milagro. Los seis personajes emergen de la oscuridad de la cuerva donde se había depositado el cadáver, iluminados por la luz procedente de la izquierda, resaltando sus marcados volúmenes y el intenso colorido de sus vestimentas.

El mismo tratamiento cromático y lumínico presenta el episodio legendario de El martirio de san Lázaro $(105 \times 60 \mathrm{~cm})$, con el santo arrodillado a la espera de recibir el tajo que un corpulento verdugo le va asestar con su espada desenvainada. Tres figuras más de soldados contemplan la escena mientras que en un tercer plano se sitúa otro a caballo. Como en el tema anterior, la composición presenta un punto de vista muy próximo al espectador, como será habitual en la obras de Villegas, donde se advierte un deseo de individualizar a los personajes, aunque el agrupamiento resulta torpe debido quizás a una excesiva intervención de taller. No 


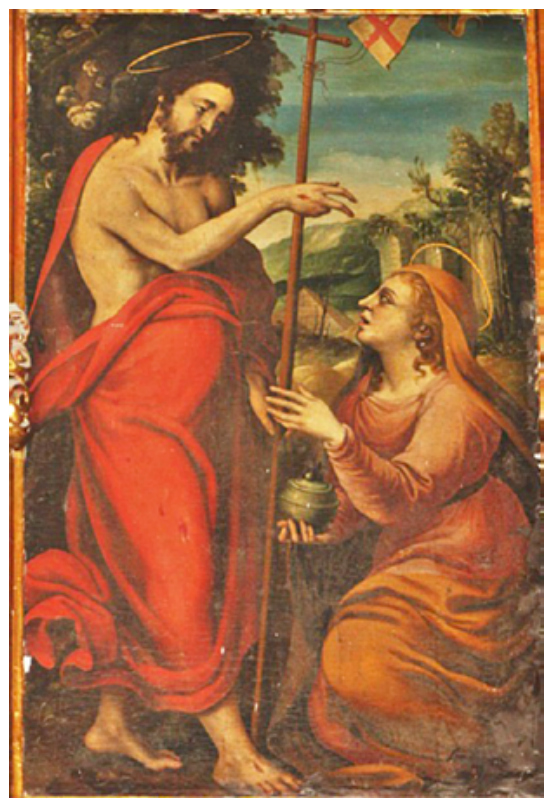

Fig. 16. Pedro de Villegas Marmolejo, Aparición de Cristo a la Magdalena o Noli me tangere, 1553, $105 \times 60 \mathrm{~cm}$, retablo mayor de la iglesia del Real Hospital de San Lázaro, Sevilla, España.

obstante, el deficiente estado que presenta la pintura no permite realizar una valoración más ajustada de sus valores plásticos.

La Aparición de Cristo resucitado a María Magdalena o Noli me tangere (No me toques) $(105 \times 60 \mathrm{~cm})$ es un tema iconográfico frecuente en el arte cristiano desde la Antigüedad y representa el episodio evangélico descrito por san Juan (20: 11-18) y san Marcos (16: 9.10), cuando Jesús se aparece por primera vez tras su resurrección a María Magdalena (figura 16). Para esta composición Villegas pudo auxiliarse del grabado de este tema realizado por Alberto Durero hacia 1511-1519. La escena se desarrolla al aire libre, en un ameno paisaje con lejanas montańas, cielo azul y ruinas arquitectónicas, donde se insertan ambas figuras, de cuerpo entero y visión de tres cuartos, dispuestas en un plano muy próximo al espectador y concebidas con sólida corporeidad y estática monumentalidad. La figura de Cristo de pie se recorta sobre el fondo verde de la arboleda que lo respalda, se halla cubierto parcialmente con manto rojo que permite ver parte de su anatomía, portando la cruz con banderola símbolo de su triunfo sobre la muerte, y adelantando su brazo derecho sobre la Magdalena, arrodillada ante él con larga cabellera suelta y llevando en su mano derecha el bote de perfume, su habitual atributo iconográfico; entre ambos se produce un emotivo cruce de miradas y un juego gestual de manos. Las figuras están trazadas mediante líneas simples y esquemáticas que marcan el volumen con un somero estudio, patente en el caso de la anatomía de desnuda de Jesús, en el que el torpe escorzo en la disposición de brazos y torso lleva a pensar en un excesiva inter- 
vención de taller o, como se ha propuesto, su realización pueda corresponder al pincel del propio Juan Chacón (Escuredo 2019).

La Magdalena penitente $(105 \times 60 \mathrm{~cm})$ se representa en su habitual iconografía como santa penitente arrepentida por sus pecados, una devoción que alcanzó una gran popularidad por su relación biográfica con Jesucristo en distintos pasajes evangélicos y por la influencia ejercida por tradiciones y leyendas medievales. Por su condición de mujer pecadora se convirtió en el prototipo de santa arrepentida y retirada para purificarse de su anterior vida licenciosa. Se halla en el centro de la composición, inserta en un paisaje abierto con amplio celaje, de cuerpo entero, sedente y con un libro abierto sobre sus rodillas. Viste recatadamente envuelta en un manto, sosteniendo el crucifijo con su mano derecha mientras su rostro, enmarcado por una larga cabellera suelta, mira hacia el rompimiento de gloria situado en el ángulo superior izquierdo de la composición. El dibujo y el colorido presentan las mismas características descritas en las anteriores pinturas del ciclo pintado por Villegas. Quedamos a la espera de que la restauración que se halla en curso permita una valoración más ajustada y completa de ésta y de todo el conjunto pictórico.

\section{VALORACIÓN PATRIMONIAL}

Tras un largo periodo de abandono y desinterés, desde hace unos años el Hospital de San Lázaro y en concreto la iglesia y sus bienes muebles que aún conserva asociados a ella han sido objeto de llamadas de atención por parte de la prensa local, asociaciones patrimonialistas y por la ciudadanía sensible hacia los bienes artísticos de la ciudad, denunciando el lamentable estado de conservación que padece todo el conjunto, pidiendo a la institución propietaria, la Junta de Andalucía, una pronta y necesaria puesta en marcha de acciones para su rehabilitación y puesta en valor.

Hemos de recordar que en 1964, por decreto de 27 de agosto, el edificio fue declarado monumento histórico-artístico, y conforme a la Ley 16/1985, de 25 de junio, del Patrimonio Histórico Español tiene la condición de Bien de Interés Cultural (BIC), está inscrito en el Catálogo General del Patrimonio Histórico Andaluz (CGPHA).

En el año 2020, por fin, la Consejería de Cultura de la Junta de Andalucía se apresta a llevar a cabo la anhelada intervención, procediendo al acuerdo con entidades colaboradoras y con el Instituto Andaluz de Patrimonio Histórico (IAPH), que se encargará de la restauración, que se ha previsto en dos fases, la primera centrada en las pinturas y esculturas del retablo y en el zócalo de azulejos del siglo XVI del presbiterio, y en una segunda fase el tratamiento in situ de la estructura arquitectónica del retablo. Finalizados estos procesos se tiene prevista la musealización del conjunto. Por tanto, se ha procedido al desmontaje de las seis pinturas y de las tallas de San José con el Niño y de Cristo crucificado, y se han depositado en el IAPH, en donde están siendo tratadas; el primer análisis técnico realizado por la institución ha revelado un alto nivel de deterioro de las pinturas que nos ocupan.

Queremos insistir en el alto valor artístico, histórico y cultural del Real Hospital de San Lázaro, de su retablo mayor y de las pinturas que lo integran y sobre la 
necesidad de su integral protección y salvaguarda que tiene asumida legalmente la institución autonómica, quien además «está obligada como propietaria del inmueble a abrir al público el templo al menos una vez a la semana" para conocimiento y disfrute de toda la ciudadanía.

Enviado: 21 de mayo de 2021; ACeptado: 24 de mayo de 2021 


\section{BIBLIOGRAFÍA}

Angulo, D. (1932). Arquitectura mudéjar sevillana de los siglos XIII, XIV y XV. Sevilla: Universidad de Sevilla.

CeÁn Bermúdez, J.A. (1800, ed. 2001). Diccionario histórico de los más ilustres profesores de las Bellas Artes. Madrid: Istmo.

Collantes de Terán y Caamaño, F. (1884). Memorias históricas de los establecimientos de caridad de Sevilla y descripción artística de los mismos (vol. I). Sevilla: Imprenta y litografía de José M. de Ariza.

Cómez, R. (1991). «El Hospital de San Lázaro en Sevilla. De Fundación medieval a edificio renacentista». Laboratorio de Arte, Sevilla: Universidad de Sevilla, n. ${ }^{\circ} 4$, pp. 43-60.

Escuredo Barrado, E. (2019). «Juan Chacón, un pintor casi desconocido en la Sevilla del xvi: un recorrido por su vida y obra». Laboratorio de Arte, Sevilla: Universidad de Sevilla, n. ${ }^{\circ} 31$, pp. $143-160$.

GonZÁlez de León, F. (1844). Noticia artística, histórica y curiosa de todos los edificios públicos, sagrados y profanos de esta muy noble, muy leal, heroica e invicta ciudad de Sevilla, (vol. II). Sevilla: Imprenta de D. José Hidalgo y Compañía.

Herrera, F.J. (2000). «El retablo de estípite», en Halcón, F., Herrera, F.J. y Recio, A. (2000), El retablo barroco sevillano. Sevilla: Universidad de Sevilla, Fundación El Monte.

López Martínez, C. (1929). Desde Jerónimo Hernández hasta Martínez Montañés. Sevilla: Rodríguez Jiménez.

Morgado, A. de (1587, ed. 2007). Historia de Sevilla, en la cual se contienen sus antigüedades, grandezas, y cosas memorables en ella acontecidas, desde su fundación hasta nuestros tiempos. Sevilla: Extramuros Ediciones.

Morales, A. (1982). «Modelos de Serlio en el arte sevillano». Archivo Hispalense: revista histórica, literaria y artística, Sevilla: Diputación Provincial de Sevilla, n. ${ }^{\circ}$ 200, pp. 149-162.

Ordenanzas del Hospital de San Lázaro, 1393. Archivo Histórico de la Diputación Provincial de Sevilla, legajo 4, 1, 1 .

Ortiz de ZúÑIga, D. (1795. ed. 1988). Anales eclesiásticos y seculares de la muy noble y muy leal ciudad de Sevilla metrópoli de la Andalucía que contienen sus principales memorias desde el año 1246 [...], (vol. I). Sevilla: Ediciones Guadalquivir.

Palomero, J.M. (1982). El retablo sevillano del Renacimiento: análisis y evolución (1560-1629). Sevilla: Diputación Provincial de Sevilla.

Réau, L. (1958). Iconographie de l'art chrétien (vol. III). París: Press Universitaires de France.

Serrera, J.M. (1991). Pedro de Villegas Marmolejo (1519-1596). Sevilla: Diputación Provincial de Sevilla.

Torre Ruiz, M.F. (1992). «Una probable obra de Roque Balduque». Atrio. Revista de Historia del Arte, Sevilla: Universidad Pablo de Olavide, n. ${ }^{\circ}$ 4, pp. 31-33.

Valdivieso, E. (1986). Historia de la pintura sevillana. Sevilla: Ediciones Guadalquivir.

Vilaplana, F. (2017). El hospital de San Lázaro en Sevilla. Origen y transformaciones. Relectura desde las aportaciones de la documentación gráfica y el estudio arquitectónico del edificio [tesis doctoral]. Universidad de Sevilla, ETS Arquitectura. https://idus.us.es/handle/11441/71195. 
Vorágine, S. (1997). La leyenda dorada (vol. iI). Madrid: Alianza Forma.

VV.AA. (1981). Guía artística de Sevilla y su provincia. Sevilla: Diputación Provincial de Sevilla. 